\title{
A integração e inclusão do sujeito com deficiência, no âmbito social e educacional
}

\author{
Penha Sebastião da Silva Rodrigues ${ }^{1}$; Gislene Farias de Oliveira ${ }^{2}$
}

\begin{abstract}
Resumo: Inclusão é a nossa capacidade de entender e reconhecer o outro, e assim ter o privilégio de co nviver e partilhar com as pessoas diferentes de nós é inclusão. A educação inclusiva deve acolher todas as pessoas sem exceção. Esta pesquisa tem como objetivo descrever sobre a integração e inclusão do sujeito com deficiência no âmbito social e educacional. Para tanto se fez necessário um estudo bibliográfico para embasar todo o desenvolvimento do mesmo, e para enriquecer buscou-se as teorias de Arantes, Ferreira \& Ferreira, Fonseca, e entre outros que deram alicerce e sustentação para a construção dos tópicos que estruturam este trabalho, que trata de uma pequena introdução aos conteúdos da pesquisa; umlevantamento sobre os conceitos de integração e inclusão, enfatizando a diferença entre um e outro além de destacar a sociedade e o sujeito com deficiência, enfatizando alguns comentários sobres às políticas voltadas para esta população, destacando também a his toria da deficiência e o que se entende sobre esse fenômeno.
\end{abstract}

Palavras-chave: Escola. Integração. Inclusão.

\section{The integration and inclusion of the individual with disabilities in social and educational context}

\begin{abstract}
Inclusion is our ability to understand and recognize the other, and thus have the privilege to live and share with people different from us is inclusion. Inclusive education should welcome all people without exception. This research aims to describe about integration and inclusion of the individual with disabilities in social and educational context. For that it was necessary a bibliographic study to support the entire development of it, and to enrich we sought to the theories of Arantes, Ferreira \& Ferreira, Fonseca, and among others that gave foundation and support for the construction of the topics that shape this work which is a brief introduction to the research content; a survey of the concepts of integration and inclusion, emphasizing the difference between them besides highlighting the company and the individual with disabilities, emphasizing some comments about the policies for this population, but also to the history of disability and what is meant on this phenomenon.
\end{abstract}

Keywords: School. Integration. Inclusion.

\section{Introdução}

A educação inclusiva pode ser definida como a prática da inclusão de todos. Assim, o objetivo deste artigo é compreender sobre a integração e inclusão do portador de deficiência na sociedade.

\footnotetext{
${ }^{1}$ Graduada em Língua portuguesa e Literatura pela Universidade EST ADUAL Vale do Acaraú- UVA; Graduada em Pedagogia pela Faculdade Kurios FAK. Pós-Graduada em Língua Portuguesa e Literatura pela Universidade Estadual Vale do Acaraú- UVA. Mestranda em Ciências da Educação Pela Anne Sullyvan University.E-E-mail: ppenhas@hotmail.com;

${ }^{2}$ Psicóloga. Doutora em psicologia Social. Pós Doutorado em Ciências da Saúde pela Faculdade de Medicina do ABC- SP. Professora da Universidade Regional do Cariri - URCA e da Universidade Federal do Cariri - UFCA.E-mail: gislenefarias@gmail.com.
} 
Buscou-se nas teorias de alguns autores de renomes subsídios para o embasamento desta pesquisa, por perceber que a dificuldade da sociedade em lidar com o diferente, a deficiência tem representado, ao longo da história, um fato que merece um estudo acerca do comportamento humano.

É comum perceber que a sociedade define a deficiência, geralmente, como algo indesejado, com limitações, uma vez que o exemplo de beleza e perfeição é definido por ela, submetendo, desta forma a pessoa com deficiência a estigmatizações, segregações e atitudes desagradáveis

Para Marques (2001, p. 35) "todas as camada que não condizem com as normas estabelecidas como naturais são de certa forma, identificadas como erradas e depositadas à margem do social".

Com base em referências bibliográficas este trabalho se encontra paltado de registros que mostram as dificuldades da sociedade em lidar com as diferenças. E se encontra dividido em três capítulos sendo o primeiro está pequena introdução aos conteúdos da pesquisa; o segundo capítulo é composto por um levantamento sobre os conceitos de integração e inclusão, enfatizando a diferença entre um e outro e o terceiro capítulo destaca a sociedade e o portador de deficiência, além de fazer alguns comentários sobres às políticas voltadas para esta população, destacando também a historia da deficiência e o que se entende sobre deficiência.

\section{Conceituando Integração}

Atualmente tem-se utilizado a palavra integração para identificar as ações de segregações, que tem como objetivo agrupar ou retirar da sociedade as pessoas que apresentam alguma deficiência ou dificuldade de adaptação. Para Bueno (2002) o termo "integração" corresponde à noção de inclusão e faz referências a níveis integrativos como, por exemplo, a integração física. Segundo o Novo Dicionário da Língua Portuguesa, Ferreira (2003, p.954) diz que a palavra integração é definida como: "do latim integratione. 1. Ato ou efeito de integrar (se). 2. Ação ou política que visa integrar um grupo as minorias raciais, 
religiosas, sociais, etc. (...)”, e revendo as questões conceituais e interpretativas sobre integração.

Santiago (1999, p.3) define: "integração é um processo. Integração é um fenômeno complexo que vai muito além de colocar ou manter excepcionais em contato com os outros. É parte da assistência que compreende todos os aspectos de um processo de inclusão". Portanto, entende-se que a integração exige uma ação das políticas adotadas e implica redefinir o papel do deficiente e a dinâmica das relações com a sociedade. Podendo, assim, repelir a idéia de família, em um espaço denominado de lar.

Acredita-se que um órgão que deve e pode colaborar para a integração de pessoas deficientes é a escola, pois, é a partir da construção de um projeto pedagógico, conscientizador, coletivo, autônomo e voltado para a diversidade que a proposta de integração começa a encontrar ressonância e a se contextualizar nos diferentes sistemas da sociedade.

Santiago (1999, p.24) diz que:

O termo integração tem aparecido as sociado ao termo inovação educacional, o qual foi utilizado na Espanha na década de 80. Refere-se a uma escola mais aberta e mais flexível para acolher uma diversidade de alunos com diferentes interesses, motivações e capacidades de aprender.

Pode-se dizer que o método de adaptação do indivíduo deve ser desenvolvido por meio de programa aberto, proporcionando um ambiente diferenciado com projetos variados e embasados com recursos e ações de inclusão, não somente aos alunos com necessidades especiais, mas também aos alunos regulares.

Santiago (1999, p.25) afirma ainda que: "a igualdade entendida como diversidade, como desenvolvimento das potencialidades educacionais através de uma oferta múltipla, pressupõe uma escolha decidida da integração escolar". Por isso, é preciso acontecer modificações positiva e concretas ao projeto pedagógico, definindo metas significativas e adequadas para a inclusão entorno da escola. Para que todos possam vislumbrar uma escola que pensa nas práticas pedagógicas que favorecer a integração social de sujeitos especiais.

De acordo com Ferreira \& Ferreira (2004, p.54) o termo integração tem, entre outros, os seguintes significados:

a) Ato ou processo de integrar, incorporação, complemento; Processo social que tende a harmonizar ou unificar diversas unidades antagônicas sejam elementos da 
personalidade dos indivíduos, dos grupos ou de agregações sociais maiores; b) Ajustamento recíproco dos membros de um grupo e sua identificação com os interesses do grupo; c) Ajustamento recíproco dos grupos, de modo a formar uma sociedade organizada; d) Ajustamento recíproco dos elementos constitutivos de uma dada cultura de modo a formar um todo equilibrado.

É fundamental que o sujeito si inclua na sociedade de modo que se sinta parte essencial dela. Para tanto é preciso que o indivíduo seja orientado para ocupar seu espaço no âmbito social, e consequentemente exercer sua cidadania, pois é provável que o especial por si mesmo, se exclua por não ter sido preparado para a integração social, fato que pode repercutir no seu desenvolvimento psíquico e cognitivo, além de contribuir para o isolamento no global.

A evolução histórica do conceito sobre inclusão indica a necessidade de um estudo mais específico embasado na diversidade de qualquer sistema social, com especialidade o educacional. Isto implica que se tem que tentar entender as divergências individuais e coletivas, com especialidade as diferenças da humanidade no âmbito escolar.

Para Arantes (2006, p.45):

\begin{abstract}
A inclusão escolar prevê intervenções decisivas e incisivas, emambos os lados: no processo de desenvolvimento do sujeito e no processo de reajuste da real-idade social [...]. Assim além de se investir no processo de desenvolvimento do indivíduo, busca-se a criação imediata de condições que garantam o aces so e a participação da pessoa na vida comunitária.
\end{abstract}

Construir a inclusão é um processo de conscientização de fundamental e essencial para o desenvolvimento e a conservação de um estado democrático, processo esse que deve ser norteado de afinidade e voltado para diversidade do sujeito especial, além de aceitar as diversidades do empenho da coletividade e da individualidade, considerando a igualdade como meio de inclusão e proporcionando a integração social em todas as extensões da vida, com especialidade no sistema educacional.

O sujeito com necessidades educativas especiais, sugere, uma pesquisa sobre a definição de "inclusão", que no entendimento de Arantes (2006, p.36) implica "estar com", "viver com o outro", sair do anonimato e fazer parte de uma coletividade.

Conforme Arantes (2006, p.47): 
Inclusão significa convidar aqueles que (de alguma forma) têm esperado para entrar e pedir-lhes para ajudar a desenhar novos sistemas que encorajem todas as pessoas a participar da completude de suas capacidades - como companheiros e como membros.

Segundo ainda a autora, inclusão constitui encontrar-se com o outro e preocupar-se uns dos outros, ação que geralmente é manifestada pelos pais, e cabendo a escola induzir os estudantes e toda comunidade escolar a fazer parte dessa integração. Referindo-se à inclusão do sujeito com necessidades educativas especiais, a mencionada autora coloca que inclusão, não é somente colocar o indivíduo em uma escola junto com os ditos "normais", pois inclusão aborda a interpretação à diversidade, de trabalhar a diferença, do procedimento como se pratica a moralidade, entre outros. Inclusão é "uma oportunidade e um catalisador para construção de um sistema democrático melhor e mais humano" (MANTOAN, 2001, p.38).

Sabe-se que a inclusão não compreende apenas garantir a matrícula dos sujeitos especiais na escola, constitui-se na concepção de modificações exemplares decorrentes da relação que se formar entre o lecionar e o aprender. Sassaki (2003, p.40) também, fala da inclusão como um novo padrão, onde:

O caminho ideal para se construir uma sociedade para todos e que por ele lutam para que possamos - juntos na diversidade humana - cumprir nossos deveres de cidadania e nos beneficiar dos direitos civis, políticos, econômicos, sociais, culturais e de desenvolvimento.

O autor, também entende a inclusão como um procedimento, que deve acontecer em várias instituições sejam públicas ou privadas, contribuindo para a superação de obstáculos e colaborando para amenizar os desafios do sistema educacional.

Sassaki (2003 p.42) diz que:

\footnotetext{
A inclusão [...], é um processo que contribui para a construção de um novo tipo de sociedade através de transformações, pequenas e grandes, nos ambientes físicos (espaços internos e externos, equipamentos, aparelhos e utensílios, mobiliários e meios de transportes) e na mentalidade de todas as pessoas, portanto também do próprio portador de necessidades especiais.
}

Sabe-se que atualmente a técnica de inclusão surge em vários segmentos sociais, mas é no sistema educacional que se dá mais ênfase para essa integração, ainda é notório a 
defasagem com relação a permanência e acesso dos especiais em certas escolas, pois, a população especial não tem ainda o lazer, o transporte e estrutura física em algumas instituições educacionais que the proporcione a sua inclusão. Neste sentido Sassaki (2003) antecipar que a sociedade como um todo deve ter como princípio aceitar as diferenças e somente assim é que poderá existir a inclusão.

\section{Integração versos inclusão}

Percebe-se que a população, com particularidade os sujeitos especiais, juntamente com as pessoas próxima, tais como professores e familiares, não tem noção da importância de saber qual diferença entre integração e inclusão, já que as duas são fundamentalmente importantes como exemplo de inclusão distinta.

Conforme Santiago (1999) na integração, o indivíduo com deficiência tem que se adequar ao sistema. $\mathrm{Na}$ inclusão, o sistema é que deve se adequar ao sujeito com deficiência. Necessário se faz destacar esta diferença, pois, às vezes no meio social, familiar e educacional a inclusão é praticada como integração. Sabe-se que vários sujeitos com deficiência são capazes de desenvolver aptidão adaptativa, pois são criaturas suficientemente evolutivas, enquanto há outras que se acomodam e atrofiam suas capacidades físicas e mentais, bem como existe tantas outras que mesmo sem incentivo procuram desempenhar seu papel na sociedade. Entende-se, assim, que é nestas peculiaridades envolventes e na relação com o meio, que se confunde a integração e a inclusão.

Santiago (1999) ainda enfatiza que o sujeito deficiente com agilidade aperfeiçoada não coloca em evidência suas habilidades com a má intenção de ser notado, apenas procurar fazer valer o seu direito de se expressar. Nesse sentido, entendendo-se, que a inclusão está sendo exercida, mas de fato, é somente um indivíduo com necessidades especiais que busca desempenhar suas habilidades no âmbito de suas limitações. Portanto, é preciso que as habilidades de todos os especiais, sem exclusões sejam adaptativas e de maneira imediata (SANTIAGO, 1999).

Partindo desta premissa se pode enfatizar também é possível que na interação, sociedade e escola encobrir seu fracasso, isolando os alunos, e apenas inclui aqueles que não 
se constituem um desafio a sua competência. Inclusão significa adaptar, e também envolvem as modificações de atitudes frente às diferenças existentes entre as pessoas (SANTIAGO, 1999). A pessoa com deficiência relacionada à socialização e a escola, as adaptações podem ser simples, mas também em muitos casos bem mais complexas. Bueno (2002, p.19) diz que existem dois tipos de adaptações:

\footnotetext{
As adaptações de grande porte ou significativas e as adaptações de pequeno porte. As primeiras são de responsabilidade mais dos gestores educacionais do que dos professores, por se tratarem de questões de ordem econômicas muitas vezes, que provem atitudes político-administrativas. Já as adaptações de pequeno porte são de responsabilidade dos professores diretamente envolvidos com as pessoas com deficiência.
}

Diante disso faz-se necessário primar pelas acomodações, tendo em vista as peculiaridades dos indivíduos com deficiência, reconhecendo as adaptações pela aquisição e manutenção da integração e da inclusão, constituindo formas de inserção social das pessoas com deficiência.

\section{Um olhar social sobre o Portador de Necessidades especiais}

Acredita-se que a insuficiência de ações práticas para a resolução dos problemas sociais, faz com que a questão da assistência social deixe de ser um tema do interesse também de algumas instituições educacionais. Segundo Ribas (1995, p.16), “[...] um valor muito cultuado na sociedade é o valor ao sucesso. O crescimento das crises sociais tem se expressado com maior ênfase na desorganização da camada pobre, aliada a violência que surge devido as desigualdades financeiras, demonstrando a deficiência ou integral incompetência da ação política e de seus detentores, bem como da ineficiência do sistema que proporciona a assistência social dos sujeitos que precisa da colaboração desses órgãos. As pessoas se dispõem numa hierarquia tal que, quem tem maior êxito nos papeis prédeterminados, maior status terá sucesso [...]". Existe na sociedade uma noção que determina o que é o êxito e o que é o sucesso e como as pessoas terão de praticar para atingi-lo. 
Id on Line Revista Multidisciplinar e de Psicologia

Id on Line Multidisciplinary Journal and Psycology

Diante disso, Carvalho (2007) afirma que na sociedade convivem indivíduos que não têm nem mesmo direito a uma sobrevivência digna, porquanto não podem nem mesmo se auto-sustentar; dentre estes indivíduos se encontram a "pessoa portadora de deficiência", que é compreendida como alguém definitivamente improdutiva e, consequentemente, excluída das relações sociais normais. De acordo com Ribas (1995, p.19):

Pensar que obstáculos sociais enfrentados pelos deficientes são absolutamente específicos e em nada dizem respeito a outros grupos ou outras frações da população é pensar que os deficientes constituem um grupo marginal de pessoas que não se enquadram ou não se adaptam na sociedade.

O capitalismo ferrenho do qual a sociedade participa é uma maléfica forma de exclusão social. Se o indivíduo é portador de qualquer deficiência, física ou mental, é que esta exclusão ocorre de forma mais ampla e profunda.

\section{As políticas}

As políticas voltadas para essa população são apenas de prevenção e detecção precoce de doenças; são insuficientes os recursos frentes à demanda; a concentração dos serviços médicos e assistências nas regiões economicamente favorecidas, que geralmente se encontram as margens dos centros urbanos, onde se encontram um maior número de casos de deficiência. A assistência oferecida às pessoas com deficiência, a organização dos serviços prestados e a sua eficácia apresentam pontos críticos.

Além desses fatores, a população deficiente é também atingida em outras necessidades, por exemplo, às vezes são impedidos de locomover-se livremente, encarando empecilhos físicos e sociais: as preocupações em adequar veículos, edifícios, ruas, telefones públicos e outros equipamentos de uso cotidiano dessa parcela da população é muito escassas (FERREIRA, 2004).

O que se percebe é que a maioria dos centros urbanos não centraliza suas reabilitações com intuito de assistir a todas as camadas sociais, pois a ineficiências de assistência nas periferias possuem escassez e quando existe é inadequado à realidade sóciocultural da clientela, onde são priorizadas as instituições organizadas por tipos de 
Id on Line Revista Multidisciplinar e de Psicologia

Id on Line Multidisciplinary Journal and Psycology

deficiência, com critérios rígidos de elegibilidade, situação econômica, grau de deficiência, grau de escolaridade e outros (CARVALHO, 2007).

\section{Considerações Finais}

Entendeu-se que o deficiente em pleno século XXI ainda é colocado à margem da sociedade e das relações sociais - caracterizando como inválido, incapaz, improdutivo desvinculado dos processos sociais produtivos da sociedade. Há que se ressaltar a importância da conscientização social, pois se acredita que por meio desse veiculo é que se encontra a base do processo de aceitação do sujeito com necessidades especiais no âmbito social.

Com base nas pesquisas bibliográficas pode-se dizer que a maior parte da problemática relacionada ao sujeito com deficiência, estar embasada na maneira de como a sociedade percebe essa população.

Compreende-se que é de fundamental importância os detentores do poder façam ser cumprida as políticas públicas que apesar de ter aparência de assistencialismo, é a única maneira, ainda, de fazer valer os direitos de todos os sujeitos com deficiências. Principalmente daqueles que se encontram distantes das periferias dos grandes centros urbanos.

\section{Referências}

AMARAL, L. A. Pensar a diferença: deficiência. (Coletânea de artigos). Faculdade Leão Sampaio. Juazeiro do Norte, 2002.

ARANTES, V. A. (Org.). Inclusão escolar: pontos e contrapontos. São Paulo: Summus Editorial, 2006.

BRASIL. Ministério da Saúde. Política Nacional de Saúde da Pessoa Portadora de Deficiência. Secretaria de Atenção à Saúde. Brasîlia: Ministério da Saúde, 2008.

Departamento de Ações Programáticas Estratégicas: Política Nacional de Saúde da Pessoa Portadora de Deficiência. Brasilia: Ministério da Saúde, 2010. 
Constituição da República Federativa do Brasil. Promulgada em 5 de outubro de 1988. 31 ed. São Paulo: Saraiva, 2003.

Saúde, 1993.

Lei Orgânica da Assistência Social - LOAS. Lei 8742. Brasilia: Ministério da Ministério da Educação. Organização Mundial da Saúde - OMS. Brasîlia: Ministério da Saúde, 1993.

2004.

Decreto $\mathbf{n}^{0}$. 5.296, de 02 de dezembro de 2004. Brasilia: Ministério da Saúde,

BUENO, J. G. S. A integração social das crianças deficientes: a função da educação especial. (Coletânea de artigos). Faculdade Leão Sampaio. Juazeiro do Norte, 2002.

CARVALHO, M. C. B. A política de assistência social no Brasil: dilemas na conquista de sua legitimidade. Revista Serviço Social \& Sociedade, ano XXVIII, nº 5, março, São Paulo, 2007.

CONADE, Conselho Nacional de Defesa da Pessoa com Deficiência. Censo de 2010 não oferecerá novamente dados confiáveis sobre pessoas com deficiência. 2010. Disponível em: http://www.mp.pe.gov.br. Acessado em nov/2011.

FERREIRA, A. B. H. Novo Dicionário Aurélio da Língua Portuguesa. São Paulo: Nova Fronteira, 2003.

FERREIRA, M. C. C.; FERREIRA, J. R. Sobre inclusão, políticas públicas e práticas pedagógicas. (Coletânea de artigos). Faculdade Leão Sampaio. Juazeiro do Norte, 2004.

FONSECA, V. Educação especial. 2 ed. Porto Alegre: Artes Médicas, 1995.

FONSECA, Ricardo Tadeu Marques da. O trabalho da pessoa com deficiência e a lapidação dos direitos humanos: o direito do trabalho, uma ação afirmativa. São Paulo: LTr, 2006.

IAMAMOTO, Marilda Vilela. O Serviço Social na contemporaneidade: trabalho e formação profissional. 14 ed. São Paulo: Cortez, 2008.

MANTOAN, M. T. E. Caminhos pedagógicos da inclusão. (Coletânea de artigos). Faculdade Leão Sampaio. Juazeiro do Norte, 2001.

MARQUES, L. P. O professor de alunos com deficiência mental: concepções e prática pedagógica. Juiz de Fora: INEP, 2001. 
MELLO, S. L. Sobrevivência no campo e na cidade. Revista Serviço Social \& Sociedade, ano XXV, no. 78, julho, São Paulo, 2004.

MIRANDA, R. Os desafios da educação especial na virada do milênio. Natal: 1999.

MONTE, F. F.; SANTOS, I. B. Saberes e práticas da inclusão. Brasilia: MEC, SEESP, 2004.

PUESEHEL, S. Síndrome de Down: guia para pais e educadores. São Paulo: Papiros, 1993.

RIBAS, J. B. C. O que são pessoas deficientes. São Paulo: Brasiliense, 1995.

SANTIAGO, M. A. A realidade dos indivíduos portadores de necessidades especiais e o processo de integração escolar em classes regulares (Coletânea de artigos). Faculdade Leão Sampaio. Juazeiro do Norte, 2001.

SASSAKI, R. K. Inclusão: construindo uma sociedade para todos. Rio de Janeiro: WVA, 2003.

Como citar este artigo (Formato ABNT):

RODRIGUES, P.S.S.; OLIVEIRA, G.F. A integração e inclusão do sujeito com deficiência no âmbito social e educacional. Id on Line Revista Multidisciplinar e de Psicologia, Set-Out de 2016, vol.10, n.31, Supl 2, p. 54-65 ISSN 1981-1179.

Recebido: 30/08/2016

Aceito: 08/09/2016 